\title{
Discussion: Hybrid anode concrete corrosion protection - independent study
}

\author{
Wayne Dodds MEng (Hons) \\ Research Engineer, AECOM Ltd, Birmingham, UK; Centre for Innovative \\ and Collaborative Construction Engineering, Loughborough University, \\ Loughborough, UK
}

Christian Christodoulou MEng (Hons), EngD, CEng, FICE, MICT Bridges and Structures District Leader, Midlands, South West \& Wales, AECOM Ltd, Birmingham, UK

Chris Goodier BEng (Hons), PhD, MCIOB, FICT, FHEA

Senior Lecturer, School of Civil and Building Engineering, Loughborough University, Loughborough, UK

\author{
Chris Atkins BEng (Hons), PhD, FICE, CEng, FICorr \\ Associate, Mott MacDonald, Altrincham, UK \\ Jim Preston BEng (Hons), CEng, FICorr, Hon.MSEE \\ Managing Director, Corrosion Prevention Limited, Cannock, UK
}

\section{Contribution by C. Atkins}

This reader would like to put forward the following comments on the paper by Dodds et al. (2016).

- In the introduction, it is stated that impressed current has been used on concrete for more than 30 years. This is contrasted with galvanic technology that has been in use for around 200 years. These statements are both correct, but galvanic technology has not been used on reinforced concrete for around 200 years. Humphry Davy did not describe its use on reinforcing steel.

- The hybrid technology described for use in concrete is a new technology, but hybrid cathodic protection of marine structures is described in BS 7361-1991 (BSI, 1991).

- Regarding paragraph 2 on p. 2 of the original paper, if a cathodic protection $(\mathrm{CP})$ system is installed, BS EN ISO 12696 (BSI, 2017) clause 6.1 requires provisions for monitoring. It is not correct that little or no maintenance is required. At the end of paragraph 3 (p. 2), it is stated that BS EN ISO 12696 (BSI, 2017) acknowledges that a holistic approach to overall conditions may be adopted for hybrid and galvanic anodes. Clause 8.6 BS EN ISO 12696 (BSI, 2017) provides four CP criteria. These are mandatory. The accompanying notes mention other alternatives discussed in the paper, but accompanying notes are informative not mandatory.

The above are issues that could have been addressed by changing the phrasing and could have been picked up at the review stage.

The Butler-Volmer equation has been used to extrapolate corrosion rates. In its application, assumptions are required for the anodic and cathodic Tafel slopes and the area that is corroding. For example, in a modelling paper by Bertolini and Redaelli (2009), a cathodic figure of $300 \mathrm{mV} /$ decade, an anodic figure of
$75 \mathrm{mV} /$ decade for corroding steel and $10 \mathrm{~V} /$ decade for passive steel were used. The paper under discussion uses $120 \mathrm{mV}$ per decade for both anodic and cathodic slopes with no mention of the variability or its effects, which could make the corrosion rate five times higher. The paper does not state the area that is assumed to be corroding. It is not stated whether this has been calculated from the reinforcement details. Even if it has, the assumption that all the current is passing to all the steel in this area has no way of being tested, and this assumption is directly proportional to the corrosion rate obtained. Both these issues should have been at least mentioned, given that there is significant variability in calculating corrosion rates based on the assumptions used. The reader appreciates that the discussion of the application of the Butler-Volmer equation is not the thrust of the paper, but the possible variabilities in calculating corrosion rate should be mentioned. It is not valid to apply the same conditions of the $1 \mathrm{~h}$ depolarisations as in Table 3 equally to the $24 \mathrm{~h}$ depolarisations in Table 5. Table 5 appears to assume that zones 1 and 2 have identical current densities, even though there are significant differences in current. This is entirely possible, but a mention in the text as to why this is the case would have been worthwhile.

\section{Contribution by J. Preston}

This reader would like to put forward the following comments on the paper by Dodds et al. (2016)

- In assessing the performance of the systems, there are several references in the paper to 'alternative criteria' and 'a holistic approach to overall condition' in respect of ISO 12696:2012 (BSI, 2012). This is not correct. There are no alternative performance criteria in this standard, and no reference to either holistic criteria or a holistic approach. The performance criteria are as stated in items (a), (b) or (c) in clause 8.6 of the standard. 
There is a requirement in the standard for an additional assessment of corrosion risk to be undertaken where galvanic anode systems do not meet the requisites (a), (b) or (c) of the criteria. This is not an additional performance criterion; it is a mandated additional assessment where galvanic anodes do not meet the performance criteria. If the $\mathrm{CP}$ system does not meet the criteria and the structure is also found to be at risk of corrosion, there is then a requirement to supplement the galvanic anode system.

In drawing conclusions, the paper relies on the standard having these 'alternative performance criteria'. As this is an incorrect interpretation of the standard, the subsequent evaluation and discussion require review.

- The paper does not identify the corrosion rate at the monitored locations prior to the installation of the system and the charge process. Are these data available? Without such data the determined low corrosion rates cannot be attributed to the efficacy of the treatment systems, and the monitored locations may simply be representative of areas of low corrosion risk.

- When using hand-held instrumentation to measure currents from galvanic anodes in concrete there can be variances in the measurements obtained, in particular as current can rapidly vary when cables are disconnected and a meter connected in series. Given the small currents measured, and the importance of the measured current in the stated calculation method for corrosion rate, how are these errors addressed?

- Certain data sets indicate negligible current or depolarisation at monitored locations, for example, in Table 3, monitoring zone 2 records $0.03 \mathrm{~mA}$ output and $1 \mathrm{mV}$ depolarisation after $24 \mathrm{~h}$. Given usual meter accuracy this could mean that the measurement has a significant error. It may be that, in reality, no current is passing, as the value may just be in the meter error range. These data are then used to demonstrate a low corrosion rate. The presented data show open-circuit potentials with what would normally be regarded as a high risk of corrosion, but applying a nominal current to the calculation indicates a low corrosion rate. Does this not highlight an error of the assessment method used?

- Is an individual steel density used for the assessment of corrosion rate at each location? How are these steel data determined when the distribution of polarisation from the anodes may vary?

- The recommendation for long-term monitoring and use of data logging facilities in Section 6 is at variance with the conclusion that the existing systems require assessment only at six yearly intervals. The latter is beyond any recommended limit in ISO 12696.

\section{Authors' reply}

The authors would like to thank the readers for their interest in the work and for putting forward a number of comments on the paper to generate discussion. The authors have discussed the comments from both submissions at length and have provided a detailed response for each point raised. The comments and responses from LE1 and LE2 (letters 1 and 2) from each reader are categorised into sub-headings, as outlined below.

\section{LE1 - Discussion letter 1 from Dr Chris Atkins}

\section{Cathodic protection criteria}

Reader's comment 1: [I]t is stated that BS EN ISO 12696 acknowledges that a holistic approach to overall conditions may be adopted for hybrid and galvanic anodes. Clause 8.6 BS EN ISO 12696 provides four CP criteria. These are mandatory. The accompanying notes mention other alternatives discussed in the paper, but the suggestions in the notes are informative, not mandatory.

Authors' response 1: While assessing the performance of cathodic protection is mandatory, this section of the standard presents a number of options. The very first paragraph of clause 8.6 states

The data collected in accordance with 8.5 shall be reviewed and interpreted in respect of the following or such criteria as modified by the particular requirements of the structure, its environment or developing expertise in respect of criteria of protection for steel in concrete.

This statement highlights that the data shall be reviewed in respect of the criteria modified by the particular requirements of the structure, its environment or developing expertise in respect of the criteria for protection of steel in concrete. Within the same clause the standard then provides a specific optout clause for galvanic systems, stated as

\section{If they [criteria for protection] are not achieved with galvanic anode systems where it is not possible to increase current to the steel, then a further assessment of corrosion risk shall be made.}

The authors have followed such guidance and good practice. The work executed and presented in the paper therefore presented the results of a corrosion-risk assessment based on the findings of a delamination and crack survey, review of past monitoring data and also corrosion current density assessment. The authors have referred to this as a 'holistic approach' to the assessment of corrosion risk.

In addition to the above, ISO 12696 acknowledges (in note 4 of clause 8.6) that the criteria outlined in clause 8.6, subclauses (a)-(c) 'are not necessarily supported by theoretical 
considerations but are a non-exhaustive, practical series of criteria to indicate adequate polarization which will lead to the maintenance or re-establishment of protective conditions for the steel within the concrete'.

It is therefore evident that ISO 12696 uses notes intentionally to provide additional guidance to users, and it clearly acknowledges its own limitations. It also explicitly recognises that this is a performance standard that utilises a number of practical series of criteria that past experience has shown to demonstrate ensuring of sufficient polarisation leading to corrosion protection.

\section{Assessment of corrosion rates}

Reader's comment 2: The Butler-Volmer equation has been used to extrapolate corrosion rates. In its application, assumptions are required for the anodic and cathodic Tafel slopes and the area that is corroding. For example, in a modelling paper by Bertolini and Redaelli (2009), a cathodic figure of $300 \mathrm{mV} /$ decade, an anodic figure of $75 \mathrm{mV} /$ decade for corroding steel and $10 \mathrm{~V} /$ decade for passive steel were used. The paper under discussion uses $120 \mathrm{mV}$ per decade for both anodic and cathodic slopes with no mention of the variability or its effects, which could make the corrosion rate five times higher.

The paper does not state the area that is assumed to be corroding. It is not stated whether this has been calculated from the reinforcement details. Even if it has, the assumption that all the current is passing to all the steel in this area has no way of being tested, and this assumption is directly proportional to the corrosion rate obtained. Both these issues should have been at least mentioned, given that there is significant variability in calculating corrosion rates based on the assumptions used. The reader appreciates that the discussion of the application of the Butler-Volmer equation is not the thrust of the paper, but the possible variabilities in calculating corrosion rate should be mentioned. It is not valid to apply the same conditions of the $1 \mathrm{~h}$ depolarisations as in Table 3 equally to the $24 \mathrm{~h}$ depolarisations in Table 5. Table 5 appears to assume that zones 1 and 2 have identical current densities, even though there are significant differences in current. This is entirely possible, but a mention in the text as to why this is the case would have been worthwhile.

Authors' response 2: As correctly acknowledged by the reader, the focus of this paper was not to provide a detailed and analytical review of the mathematical limitations of the Butler-Volmer equation. The paper solely reports the results of a corrosion risk analysis undertaken on full-scale structures on which hybrid anodes were installed, and their associated performance.
The authors provided citations for the original Butler-Volmer equation, which were subsequently used to perform corrosion current density calculations. These citations provide adequate explanation and further references to the mathematical and experimental analysis undertaken on the accuracy and sensitivity of the Butler-Volmer equation (Christodoulou et al., 2010). Further research was also undertaken into the accuracy and variability of corrosion current densities using both polarisation resistance and transient response methods, acknowledging their limitations, together with proposed improvements for accuracy and consistency by developing an alternative circuit model and associated mathematical derivation of corrosion current density from the frequency to the time domain (Christodoulou et al., 2012).

A Tafel constant of $120 \mathrm{mV}$ has a sound theoretical basis for any reaction in which the rate determining step involves the transfer of two electrons across an activation energy barrier. Furthermore, most of the data that were used to generate the corrosion classifications in Concrete Society Technical Report 60 (TR60) (Concrete Society, 2004), including 'very low or passive' (up to $2 \mathrm{~mA} / \mathrm{m}^{2}$ ) and 'high', relied on this same constant. The authors therefore would argue this is a good engineering choice.

The authors agree that the actual area of steel corrosion has a large effect on corrosion rates. For example, in TR60, a corrosion rate of $10 \mathrm{~mA} / \mathrm{m}^{2}$ is classified as high, but only equates to $12 \mu \mathrm{m}$ of reinforcement section per year, which is relatively small. The reason that it is classified as high is because it may equate to $120 \mu \mathrm{m}$ per year if $90 \%$ of the steel surface, where the measurement was made, remained passive. A simple mathematical sensitivity analysis with the Butler-Volmer equation was performed in the paper to highlight the significant variability in calculating corrosion rates based on the assumptions used (p. 10, paragraphs 6 and 7).

It is stated in the methodology section that a 'desk study was first conducted to review previous principal inspection reports, existing monitoring data and as-built drawings, where available'. The authors feel this is a clear statement that as-built information has been used where available to determine the surface area of steel reinforcement and the subsequent current densities.

Table 3 shows the depolarisation data for a period of $1 \mathrm{~h}$. While the authors agree a $24 \mathrm{~h}$ depolarisation period is preferred, access restrictions to the site meant that it was not possible to obtain full depolarisation data for this structure. Furthermore, anything less than full depolarisation $(24 \mathrm{~h})$ will generate a higher corrosion rate and will therefore be conservative. The authors have acknowledged the limitation of restricted access by recommending remote monitoring of newly installed systems to obtain long-term monitoring data, 
particularly on sites where traffic management may be required (p. 11, paragraph 5). Corrosion rates should preferably be used in conjunction with the results of a visual assessment, which was covered in this study. These structures are still in a visually good condition with no visible evidence of corrosion-induced deterioration.

\section{Standard monitoring requirements and maintenance}

Reader's comment 3: [I]f a CP system is installed, BS EN ISO 12696 clause 6.1 requires provisions for monitoring. It is not correct that little or no maintenance is required.

Authors' response 3: The authors would agree that the standard requires monitoring, and this is not disputed in the paper (p. 2, paragraph 2).

Regarding the maintenance of hybrid systems, the informative section in annex A of the standard describes cathodic protection as the objective to

shift the steel/concrete potential into a region where if corrosion has already started, the continuation/propagation of corrosion; is so far suppressed that a corrosion failure is unlikely during the lifetime of the structure.

Cathodic protection commonly achieves this with a power supply and the end-user has the liability to maintain that power supply for the lifetime of the structure.

The authors abide by their statement that galvanic and hybrid systems require little or no maintenance as there is no power supply to maintain, hence maintenance requirements are reduced. Various research papers discuss the reduced maintenance requirements of galvanic systems compared with impressed current systems (Broomfield, 2000; Byrne et al., 2016; Polder, 1998; Polder et al., 2014; Sohanghpurwala, 2009; Wilson et al., 2013). Such technologies are based on the principle of galvanic cells, which do not require mechanical and electrical equipment that would need a relatively higher level of maintenance and also have a manufacturerdisclosed annual maintenance cycle, service life and replacement life.

Less frequent monitoring may also be required as the system utilises a temporary impressed current treatment to arrest steel corrosion and change the environment of the steel. As a consequence, the long-term current requirement is reduced. Hybrid corrosion protection also utilises the responsive nature of sacrificial anodes to changes in the environment. Warm, wet conditions generally give rise to high protection currents associated with a higher corrosion risk. No protection current is needed under very cold or dry conditions.

\section{History of cathodic protection}

Reader's comment 4: In the introduction, it is stated that impressed current has been used on concrete for more than 30 years. This is contrasted with galvanic technology that has been in use for around 200 years. These statements are both correct, but galvanic technology has not been used on reinforced concrete for around 200 years. Humphry Davy did not describe its use on reinforcing steel. The hybrid technology described for use in concrete is a new technology, but hybrid cathodic protection of marine structures is described in BS 7361-1991 (BSI, 1991).

Authors' response 4: The authors would agree that while sacrificial cathodic protection has been around for a long time, it has not been very successful in reinforced concrete applications due to the high resistivity of concrete and the relatively low current output of sacrificial anodes. Developments such as hybrid corrosion protection attempt to address this. The reference to Humphry Davy's work within the text serves to demonstrate when this technology first became scientifically known.

Hybrid corrosion protection of steel in concrete is a relatively new technology (patented in 2006 and commercially available since then) and is not the same as a similarly named form of cathodic protection used in sea water.

\section{LE2 - Discussion letter 2 from Jim Preston}

\section{Cathodic protection criteria}

Reader's comment 5: In assessing the performance of the systems, there are several references in the paper to 'alternative criteria' and 'a holistic approach to overall condition' in respect of ISO 12696:2012 (BSI, 2012). This is not correct. There are no alternative performance criteria in this standard, and no reference to either holistic criteria or a holistic approach. The performance criteria are as stated in items (a), (b) or (c) in clause 8.6 of the standard.

There is a requirement in the standard for an additional assessment of corrosion risk to be undertaken where galvanic anode systems do not meet the requisites (a), (b) or (c) of the criteria. This is not an additional performance criterion; it is a mandated additional assessment where galvanic anodes do not meet the performance criteria. If the $\mathrm{CP}$ system does not meet the criteria and the structure is also found to be at risk of corrosion, there is then a requirement to supplement the galvanic anode system.

In drawing conclusions, the paper relies on the standard having these 'alternative performance criteria'. As this is an incorrect interpretation of the standard, the subsequent evaluation and discussion require review. 
Authors' response 5: This is a very similar discussion to that raised by Dr Chris Atkins (LE1, reader's comment 1). The authors have followed the guidance and good practice stated in clause 8.6 of ISO 12696 throughout this study. The authors feel that this comment has been addressed in its entirety in authors' response to section 1 above (LE1).

\section{Assessment of corrosion rates}

Reader's comment 6: The paper does not identify the corrosion rate at the monitored locations prior to the installation of the system and the charge process. Are these data available? Without such data the determined low corrosion rates cannot be attributed to the efficacy of the treatment systems, and the monitored locations may simply be representative of areas of low corrosion risk.

When using hand-held instrumentation to measure currents from galvanic anodes in concrete there can be variances in the measurements obtained, in particular as current can rapidly vary when cables are disconnected and a meter connected in series. Given the small currents measured, and the importance of the measured current in the stated calculation method for corrosion rate, how are these errors addressed?

Certain data sets indicate negligible current or depolarisation at monitored locations, for example, in Table 3, monitoring zone 2 records $0.03 \mathrm{~mA}$ output and $1 \mathrm{mV}$ depolarisation after $24 \mathrm{~h}$. Given usual meter accuracy this could mean that the measurement has a significant error. It may be that, in reality, no current is passing, as the value may just be in the meter error range. These data are then used to demonstrate a low corrosion rate.

The presented data show open-circuit potentials with what would normally be regarded as a high risk of corrosion, but applying a nominal current to the calculation indicates a low corrosion rate. Does this not highlight an error of the assessment method used?

Is an individual steel density used for the assessment of corrosion rate at each location? How are these steel data determined when the distribution of polarisation from the anodes may vary?

Authors' response 6: It is stated within Section 2 of the paper, alongside background information for each structure assessed, that refurbishment works were conducted following reports of substantial spalling and delamination, high chloride concentrations and signs of corrosion activity. It is therefore reasonable to assume that the structure was at high risk prior to the repair work, and in fact hybrid anodes were installed in these areas of prior corrosion activity. The corrosion rates prior to the installation of the corrosion protection system are not known and thus not reported. This limitation of the work is clearly identified.

With regard to the location of reference electrode installation, ISO 12696:2016 (BSI, 2017) cites

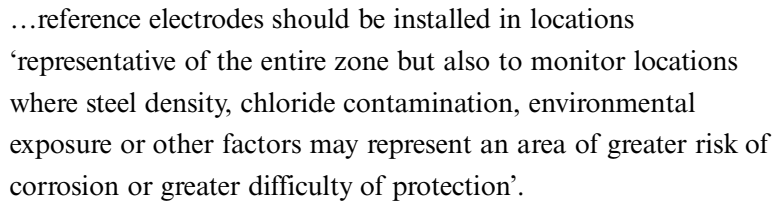

Additionally, as data collected may be 'disrupted by the presence of concrete repairs encompassing reinforcement or other steel within $0.5 \mathrm{~m}$ of the point of measurement of potential', reference electrodes should be positioned away from concrete patch repair areas where possible.

The hybrid anode installations surveyed as part of this work were all installed and commissioned under the supervision of a qualified CP Level 3 engineer, and as such it is reasonably expected that the installations are fully compliant with the requirements of ISO 12696:2016 (BSI, 2017) and the current versions of it at the time of the installation of these systems.

While there were no prior corrosion current density assessments available, the monitoring data presented in the paper (refer to Figures 4, 6 and 8) illustrate the beneficial effect of the hybrid anode system with an observed passive trend of steel 'on' potential with time towards more positive values, with resting steel on potentials for the three systems shifting positively; all of which are considered to be clear indications of passive conditions at the steel interface.

All of the above demonstrate that the hybrid anode systems are functioning as expected with the steel in a passive condition, and the authors have recommended that it would be beneficial to obtain long-term monitoring data for all new systems installed, to provide additional data for a holistic assessment (p. 11, paragraph 5).

The reader makes reference to the possible variance in current measurements obtained and the importance of the measured current in the stated calculation method for corrosion rate. This is a similar discussion to that raised by Dr Chris Atkins (LE1, reader's comment 2). The authors feel that this comment has been addressed in its entirety in authors' response 2 above (LE1) regarding the sensitivity of the Butler-Volmer equation and the accuracy and variability of corrosion current densities using both polarisation resistance and transient response methods (Christodoulou et al., 2010, 2012). 
The authors discuss in the paper that the small currents measured, combined with a passive trend in steel 'on' potential and the results of visual inspection are representative of a benign environment with passive reinforcement (p. 10, paragraph 5). This statement is further supported by published research on the 'responsive behaviour' of galvanic anodes, whereby lower currents are delivered by galvanic anodes when there is a lower risk of corrosion initiation (Holmes et al., 2011; Sergi, 2011).

With regard to the absolute values of depolarised steel potentials, these are typically assessed against the criteria stated in ASTM C876-2009 (ASTM, 2009). The standard aims to provide general guidance with regard to the probability of corrosion occurring. However, it is recognised that the results could be affected by numerous factors such as temperature, $\mathrm{pH}$, moisture, oxygen permeability, concrete bulk resistivity and several others. The standard itself also acknowledges that there is a substantial area of uncertainty.

Furthermore, TR60, cites

As the criteria were devised empirically, variations can occur for different types of concrete, for which the ASTM criteria cannot usefully be used. Because of the limitations of this approach, alternative methods of assessment have become more common.

As such, the authors have not relied on absolute values alone when undertaking the corrosion risk assessment but rather, took a holistic approach of reviewing such absolute values based on time elapsing and also environmental and condition factors that overall give a substantially greater level of certainty about the condition of the reinforcement.

The final paragraph of the reader's discussion is similar to that raised by Dr Chris Atkins (LE1, reader's comment 2). As previously discussed, the authors made it clear in the paper that as-built information was used where available to determine the surface area of steel reinforcement and subsequent current densities.

\section{Standard monitoring requirements and maintenance}

Reader's comment 7: The recommendation for long-term monitoring and use of data logging facilities in Section 6 is at variance with the conclusion that the existing systems require assessment only at six yearly intervals. The latter is beyond any recommended limit in ISO 12696.

Authors' response 7: The authors would like to clarify that there was no intention to contradict the requirements of ISO 12696. The concluding paragraph of the paper acknowledges that this work was the first of its kind to use a holistic approach to corrosion-risk assessment, and the authors' recommendation was that, as a minimum, this holistic approach should be combined with principal inspection intervals. Such a proposal is not unreasonable, when considering that highly stressed, load-bearing primary structural elements are safely operational with inspections at six yearly intervals. The overall condition and operability significance of such structural elements far outweigh any operational risks of electrochemical protection systems.

\section{REFERENCES}

ASTM (2009) C876-09: Standard test method for corrosion potentials of uncoated reinforcing steel in concrete. ASTM International, West Conshohocken, PA, USA.

Bertolini L and Redaelli E (2009) Throwing power of cathodic prevention applied by means of sacrificial anodes to partially submerged marine reinforced concrete piles: results of numerical simulations. Corrosion Science 51(9): 2218-2230.

Broomfield JP (2000) The Principles and Practice of Galvanic Cathodic Protection for Reinforced Concrete Structures. Corrosion Prevention Association, Bordon, UK, Technical note 6.

BSI (1991) BS 7361-1:1991: Cathodic protection. Code of practice for land and marine applications. BSI, London, UK.

BSI (2012) BS EN ISO 12696:2012: Cathodic protection of steel in concrete (withdrawn). BSI, London, UK.

BSI (2017) BS EN ISO 12696:2016: Cathodic protection of steel in concrete. BSI, London, UK.

Byrne A, Holmes N and Norton B (2016) State-of-the-art review of cathodic protection for reinforced concrete structures. Proceedings of the Institution of Civil Engineers - Magazine of Concrete Research 68(13): 664-677, https://doi.org/10.1680/jmacr.15.00083.

Christodoulou C, Glass G, Webb J, Austin S and Goodier C (2010) Assessing the long term benefits of impressed current cathodic protection. Corrosion Science 52(8): 2671-2679.

Christodoulou C, Goodier C, Austin S, Webb J and Glass G (2012) On-site transient analysis for the corrosion assessment of reinforced concrete. Corrosion Science 62: 176-183, http://doi.org/10.1016/ j.corsci.2012.05.014.

Concrete Society (2004) TR60 Electrochemical Tests for Reinforcement Corrosion. Concrete Society, Camberley, UK. Technical Report 60.

Dodds W, Christodoulou C and Goodier C (2016) Hybrid anode concrete corrosion protection - independent study. Proceedings of the Institution of Civil Engineers - Construction Materials, http://dx.doi.org/10.1680/jcoma.16.00024.

Holmes SP, Wilcox GD, Robins PJ, Glass GK and Roberts AC (2011) Responsive behaviour of galvanic anodes in concrete and the basis for its utilisation. Corrosion Science 53(10): 3450-3454.

Polder RB (1998) Cathodic protection of reinforced concrete structures in the Netherlands - experience and developments: cathodic protection of concrete - 10 years experience. Heron 43(1): 3-14.

Polder RB, Leegwater G, Worm D and Courage W (2014) Service life and life cycle cost modelling of cathodic protection systems for concrete structures. Cement and Concrete Composites 47: 69-74, http://doi.org/10.1016/j.cemconcomp.2013.05.004.

Sergi G (2011) Ten-year results of galvanic sacrificial anodes in steel reinforced concrete. Materials and Corrosion 62(2): 98-104.

Sohanghpurwala AA (2009) Cathodic Protection for Life Extension of Existing Reinforced Concrete Bridge Elements. Transportation Research Board, Washington, DC, USA.

Wilson K, Jawed M and Ngala V (2013) The selection and use of cathodic protection systems for the repair of reinforced concrete structures. Construction and Building Materials 39: 19-25, http://doi.org/10.1016/j.conbuildmat.2012.05.037. 